REVIEW

\title{
Device based treatment of heart failure
}

\author{
A Y Patwala, D J Wright
}

Postgrad Med J 2005;81:286-291. doi: 10.1136/pgmj.2004.026716

As the population ages and survival from ischaemic heart disease improves, the incidence and prevalence of congestive cardiac failure has increased dramatically. Medical treatments including ACE inhibitors, $\beta$ blockers, and aldosterone antagonists have improved the outlook for most patients. However, despite optimal medical treatment there is a significant group of patients who continue to suffer poor morbidity and mortality. Device based treatment consisting of implantable cardioverter defibrillators (ICD) and cardiac resynchronisation therapy (CRT) devices offer new modes of treatment to patients with symptomatic heart failure despite optimal medical therapy. ICDs have been shown to reduce mortality in patients with severe heart failure while CRT leads to an improvement in functional class, quality of life scores, physiological measures such as peak $\mathrm{VO}_{2}$, and reduce hospitalisations. Combination devices, which provide both ICD and CRT functions, have now been seen to provide synergistic benefits in selected patients.

See end of article for authors' affiliations

Correspondence to: Dr A Patwala, The Cardiothoracic Centre, Thomas Drive, Liverpool L14 3PE, UK; a_patwala@ lineone.net

Submitted 12 July 2004 Accepted

19 September 2004

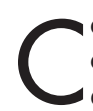
ongestive cardiac failure is a common condition, which has now reached epibetween $1 \%$ and $3 \%$ of the general population ${ }^{12}$ and increases with age to affect $10 \%$ of those over $70{ }^{2}$ This represents only those patients who are symptomatic, in a recent population based study in England it was shown that the prevalence of left ventricular (LV) systolic dysfunction (defined as an ejection fraction (EF) $<40 \%$ ) in patients aged 45 years and above was $1.8 \%$, and of these $47 \%$ had no symptoms. ${ }^{1}$ As the population ages and survival from ischaemic heart disease improves the prevalence is likely to increase further. In a simulation model it was shown that between 1985 and 2010 there is likely to be a $70 \%$ increase in absolute numbers of heart failure patients. ${ }^{3}$ In the past decade there have been many important advances in the pharmacological treatment of heart failure, however the condition continues to exact a heavy burden in terms of mortality and morbidity. ${ }^{4}$ Death attributable to heart failure may be sudden (usually arrhythmic) or attributable to progressive heart failure ${ }^{5}$ with gradual deterioration in symptoms. The one year mortality has been shown to increase with worsening symptomatic heart failure. This was 5\%-15\% for NYHA class II, $20 \%-50 \%$ for class III, and $>50 \%$ for class IV. ${ }^{6-8}$ The five year mortality after the demic proportions. In the UK it affects diagnosis of heart failure remains about $50 \%$. $^{9-11}$ In the UK heart failure has been reported to consume more than $2.5 \%$ of the total healthcare expenditure. ${ }^{2}$ With such continued impact from heart failure we require new modes of treatment in addition to those currently available to improve mortality and morbidity.

\section{MEDICAL TREATMENTS}

Pharmacological treatment for heart failure is described in the NICE guidelines ${ }^{12}$ and is designed to improve symptoms and reduce mortality. In heart failure there is overexpression of components of the renin-angiotensin-aldosterone and sympathetic nervous systems. This has been shown to suppress myocardial function, cause myocardial hypertrophy and myocyte apoptosis leading to mural thinning and progressive dilatation. ${ }^{13}$ Therefore modulation of these neurohormonal changes has become the cornerstone of treatment. Three main classes of drugs have been shown to improve mortality and symptoms namely drugs affecting the reninangiotensin system (including angiotensin converting enzyme (ACE) inhibitors and angiotensin II type 1 receptor blockers (ARB)), $\beta$ adrenoceptor blockers, and aldosterone antagonists.

There have been 34 trials assessing ACE inhibitors in heart failure. A review of all 34 trials showed a significant reduction in total mortality $(p<0.001)$ and combined end point of mortality or hospitalisation $(\mathrm{p}<0.001) .{ }^{14}$ In animal models it has been shown that despite adequate ACE inhibition there is still near normal production of angiotensin II, via ACE independent pathways, within the myocardium. ${ }^{15}$ It was therefore postulated that block of the renin-angiotensin system at the angiotensin II type 1 receptor level would be more beneficial than ACE inhibition. In a metaanalysis of 17 trials looking at ARB the results showed that when ARB were compared with placebo there was a non-significant trend towards improved survival $(p=0.19)$ and decreased hospitalisation $(p=0.33)$ with ARB treatment. When ARB were compared with ACE inhibitors there was no difference in survival or hospitalisation and when ARB were added to ACE inhibitors and compared with ACE inhibitors alone there was no difference in mortality but there was a significant reduction in hospitalisation $(\mathrm{p}<0.0001) .{ }^{16}$

Abbreviations: ICD, implantable cardioverter defibrillator; CRT, cardiac resynchronisation therapy; $A C E$, angiotensin converting enzyme; $A R B$, angiotensin receptor blocker; $\mathrm{MI}$, myocardial infarction; EPS electrophysiological study; RV, right ventricular; LV, left ventricular; BiV, biventricular; $\mathrm{EF}$, ejection fraction 
$\beta$ Adrenoceptor blockers have been shown to significantly improve the functional status $(\mathrm{p}=0.04),{ }^{17}$ reduce hospitalisation $\left((p<0.01)^{17}(p=0.036)^{18}\right)$, reduce all cause mortality $\left((p=0.0062)^{5}(p<0.001)^{18}(p<0.0001)^{19}\right)$, and reduce sudden death $\left((p=0.0002)^{5}(p=0.0011)^{19}\right)$.

Two main aldosterone antagonists, namely spironolactone and eplerenone, have been studied in addition to standard treatment, and both produced a significant reduction in mortality $\quad\left((\mathrm{p}<0.001)^{20} \quad(\mathrm{p}=0.008)^{21}\right)$ and morbidity $\left((p<0.001)^{20}(p=0.002)^{21}\right)$. Further symptomatic treatment is achieved using diuretics and digoxin. ${ }^{22}$

A combination of the above drugs is now widely accepted as being the optimum medical treatment for heart failure however it has been shown that full implementation of evidence based doses is rarely achieved in clinical practice. ${ }^{23-25}$ This is despite the fact that clinical studies have shown that ACE inhibitors at maximum doses are well tolerated by around $80 \%-90 \%$ of patients with chronic heart failure. ${ }^{26}{ }^{27}$ The ATLAS trial has shown the importance of achieving the maximum tolerated dose. In this large scale trial it was shown that there was a greater benefit to be gained from high dose (32.5-35 mg) compared with low dose (2.5-5 mg) lisinopril in patients with heart failure. ${ }^{28}$ Unfortunately in a substantial number of patients despite receiving optimal medical treatment they continue to suffer with poorly controlled symptoms and a high risk of death. ${ }^{18}{ }^{29-32}$ Device based treatment offers new options to prevent both sudden death and death attributable to progressive heart failure using implantable cardioverter defibrillators and cardiac resynchronisation therapy devices respectively. ${ }^{30}$

\section{IMPLANTABLE CARDIOVERTER DEFIBRILLATORS}

The mechanism of sudden death in heart failure patients was assessed in a sub-study of the ATLAS trial. This found that $51 \%$ of patients with sudden death had a causative primary arrhythmic event. ${ }^{33}$ In view of this high incidence of potentially reversible arrhythmia many trials have evaluated ways of preventing sudden death.

Initially antiarrhythmic drugs were used in post-myocardial infarction (MI) patients with impaired LV function. CAST and CAST II used class I antiarrhythmic agents (encainide, flecainide, or moricizine) compared with placebo. Both trials were terminated prematurely because of increased mortality $\left((\mathrm{p}=0.0004)^{34}(\mathrm{p}=0.40)^{35}\right)$ in the antiarrhythmic group. In view of these results the focus switched to amiodarone, and to date there have been 13 randomised trials performed. ${ }^{36-48}$ Only three of these have reported a significant reduction in overall mortality..$^{36-38}$ A meta-analysis of all 13 trials showed that there was a 13\% reduction in mortality with amiodarone $(p=0.03)$ and a $29 \%$ reduction in arrhythmic death $(\mathrm{p}=0.0003)$. There was virtually no effect of amiodarone on non-arrhythmic death. ${ }^{49}$

In the mid-1990s attention began to switch towards the use of ICDs. Initially ICDs were compared against antiarrhythmic agents (mainly amiodarone) in patients who had been resuscitated from ventricular arrhythmias. Three large scale multicentre trials have been carried out. AVID found a significant reduction in mortality in the ICD group $(\mathrm{p}<0.02),{ }^{50}$ CIDS found a non-significant $19.7 \%$ reduction in all cause mortality $(\mathrm{p}=0.142)$ and a non-significant $32.8 \%$ reduction in the risk of arrhythmic mortality with ICD therapy $(\mathrm{p}=0.094),{ }^{51}$ and CASH found a non-significant $23 \%$ reduction in all cause mortality in the ICD group $(p=0.081) .^{52}$ A meta-analysis showed that there was an overall $28 \%$ reduction in mortality $(p=0.0006)$ and that this was entirely attributable to a $50 \%$ reduction in arrhythmic deaths $(\mathrm{p}<0.0001)$. The meta-analysis also showed that patients with a LVEF $>35 \%$ had significantly less benefit from ICD than those with a EF $<35 \%(p=0.011) .^{53}$

ICDs were thus established as the treatment of choice in preventing sudden death in patients after resuscitation for ventricular arrhythmias. The next step was to decide whether non-arrest but high risk patients would benefit from ICDs. The high risk group initially identified were patients with LV dysfunction after MI with history of non-sustained ventricular tachycardia (at least three beats) and a positive electrophysiological study (EPS) (defined as inducible nonsuppressible ventricular tachyarrhythmias). The two trials looking at this were MADIT I and MUSTT. Both studies randomised patients to treatment with either an ICD or conventional treatment. MADIT I found a 54\% reduction in mortality with ICD treatment $(p=0.009)^{54}$ while MUSTT showed a $76 \%$ reduction in cardiac arrest or death from arrhythmia in patients treated with an ICD $(\mathrm{p}<0.001) .{ }^{55}$ The MUSTT trial also showed treatment with serial electrophysiological drug testing without ICD back up, even when a drug was found that effectively suppressed VT induction, had no significant benefit compared with no treatment. ${ }^{56}$

The MADIT II trial researchers reasoned that in patients with a prior MI and advanced LV dysfunction the scarred myocardium would serve as a substrate for ventricular arrhythmia, and therefore EPS testing would not be required for risk stratification. ${ }^{57}$ They therefore took 1232 patients with a history of a previous $\mathrm{MI}$ and an EF $<30 \%$ and randomised them, without any further testing, to either implantation of a ICD or conventional treatment. In the group with an ICD there was a $31 \%$ reduction in mortality compared with optimal conventional treatment $(p=0.016)$. The greatest reduction was seen in those patients with a QRS width $>150 \mathrm{~ms}^{58}$ Despite EPS inducibility not being an inclusion criteria 593 patients in the ICD arm underwent EPS testing at the time of ICD implantation. EPS inducibility at baseline did not differentiate between those who were more likely to require ICD therapy for termination of ventricular tachycardia or fibrillation from those who were not. ${ }^{59}$

Most recently the results from SCD-HeFT were reported at the American College of Cardiology's annual scientific session (March 2004). This study took 2521 patients with ischaemic or non-ischaemic NYHA class II and III chronic heart failure and EF $<35 \%$, and compared the effects of ICD with amiodarone and with placebo on all cause mortality. There was no significant difference between the placebo and amiodarone group, however the ICD group had a significant $23 \%$ reduction in mortality $(p=0.007)$. The improvement in mortality was independent from the aetiology of the heart failure and the benefit was greater in the group with NYHA class II, rather than class III, heart failure. ${ }^{60}$

ICD therapy has therefore become the treatment of choice in primary and secondary prevention of ventricular arrhythmias. Table 1 shows the current NICE guidelines for ICD implantation. However, while it is known that ICDs reduce sudden death, it has now been shown that recurrent ICD discharges are associated with psychological disturbances. ${ }^{61}$ Therefore the combination of antiarrhythmic drugs and ICDs are now being investigated. In the only double blinded trial looking at the addition of an antiarrhythmic to patients with a ICD, it was shown that the addition of sotalol led to a $48 \%$ reduction in death or first ICD shock $(\mathrm{p}<0.001) .{ }^{62}$ The evidence for amiodarone is less robust, the CASCADE study was designed to compare amiodarone with EPS guided therapy, however during the course of the trial ICD placement became standard to both groups and in the amiodarone group there were significantly fewer shocks associated with syncope $(p=0.032)$ and a non-significant reduction in total number of shocks $(p=0.14)^{63}$ 
Table 1 Current NICE guidelines for ICD implantation

Secondary prevention

Cardiac arrest attributable to either ventricular tachycardia (VT) or ventricular fibrillation (VF)

Spontaneous sustained VT causing syncope or significant haemodynamic compromise

Sustained VT without syncope/cardiac arrest, and who have an associated reduction in ejection fraction (less than 35\%) but are no worse than III of New York Heart Association functional classification of heart failure.

Primary prevention

A history of previous myocardial infarction (MI) and: non-sustained VT on Holter (24 hour ECG) monitoring. Inducible VT on electrophysiological testing.

Left ventricular dysfunction with an ejection fraction (EF) less than $35 \%$ and no worse than III of the New York Heart Association functional classification of heart failure.

A familial cardiac condition with a high risk of sudden death, including long QT syndrome, hypertropic cardiomyopathy, Brugada syndrome, arrhythmogenic right ventricular dysplasia (ARVD), and after repair of tetralogy of Fallot.

\section{CARDIAC RESYNCHRONISATION THERAPY}

Conduction system delay (for example, LBBB) occurs as a consequence of the underlying pathophysiological disease in patients with chronic heart failure and results in dyssynchronous ventricular contractions. This triggers adaptive chamber dilatation and neurohormal stimulation ${ }^{64}$ leading to diminished contractile reserve of the heart ${ }^{65}$ and inefficient myocardial contraction. ${ }^{6}{ }^{6}$ The mean QRS duration increases as the severity of chronic heart failure increases. The percentage of people with a QRS $>120 \mathrm{~ms}$ has been shown to be $9.7 \%$ for New York Heart Association (NYHA) class 0-I, $32 \%$ for NYHA class II, and 53\% for NYHA class III. ${ }^{31}$ In a substudy of the VEST trial increased QRS width was a independent predictor of mortality $(p<0.0001){ }^{67}$

Studies were devised to reverse LBBB using temporary pacing wires connected to an external pacemaker box, delivering right ventricular (RV), left ventricular (LV), or biventricular (BiV) pacing. These studies showed RV pacing led to no significant improvement over no pacing. ${ }^{68-70} \mathrm{BiV}$ and LV pacing was shown to increase the mean cardiac index $(\mathrm{p}<0.006){ }^{68}$ decrease the pulmonary capillary wedge pressure $(p<0.01){ }^{68}{ }^{70}$ decrease mean $V$ wave $\left((p<0.004)^{68}\right.$ $\left.(\mathrm{p}<0.001)^{70}\right)$, increase the systolic blood pressure $\left((p<0.03)^{70}(p<0.0001)^{71}\right)$, and increase the maximum LV pressure derivative $\left((p<0.01)^{69} \quad(p<0.0001)^{71}\right)$. In some of these studies LV pacing had a more beneficial effect than BiV pacing $\left((\mathrm{p}<0.05)^{69}(\mathrm{p}<0.01)^{71}\right)$. This may have been attributable to the fact that in the BiV pacing group there was synchronous stimulation of both ventricles however this does not recapture the normal activation of the two ventricles and therefore may be suboptimal. ${ }^{72}$
In view of these acute haemodynamic changes CRT devices were developed with right atrial and ventricular leads as seen in a dual chamber pacemaker and an additional lead that is passed through the coronary sinus to the LV free wall (see fig 1). The pacemaker can then mimic the intrinsic conduction system and ensure that atrial and synchronised ventricular contractions occur to achieve optimal cardiac function and thereby improve symptoms (see fig 2).

Initially small scale observational studies, including PATHCHF $(n=41),{ }^{73}$ MUSTIC $(n=67)^{74}$ and the multicentre InSync study $(\mathrm{n}=103),{ }^{75}$ were carried out to assess the effects of CRT on symptoms and functional capacity. All the patients were receiving optimal medical treatment but still had persistent symptoms. Treatment with a CRT device led to an improvement in quality of life scores $(\mathrm{p}<0.001){ }^{73-75}$ NYHA class $(p<0.001),{ }^{73}$ six minute walk test distance $(p<0.001),{ }^{73-75}$ peak $\mathrm{VO}_{2}\left((\mathrm{p}<0.001)^{73}(\mathrm{p}<0.03)^{74}\right)$, and decreased hospitalisations $(\mathrm{p}<0.05) .^{74}$ In addition CRT was shown to reduce myocardial oxygen consumption ${ }^{76}$ which is most probably because of decreased LV wall stress through improved coordination of the wall contractions. ${ }^{77} 78$ This is significant as most heart failure treatments directly increasing systolic function do so while also increasing myocardial oxygen consumption. The only other treatment shown to reduce myocardial oxygen consumption but improve systolic function is $\beta$ block. ${ }^{65}$ Corresponding to these haemodynamic and functional benefits, studies have also shown that CRT leads to a reduction in the LV end diastolic and end systolic volumes and also a improved myocardial performance index. ${ }^{75} 7980$

The MIRACLE trial was the first large scale randomised clinical trial looking at CRT in heart failure. A total of 453
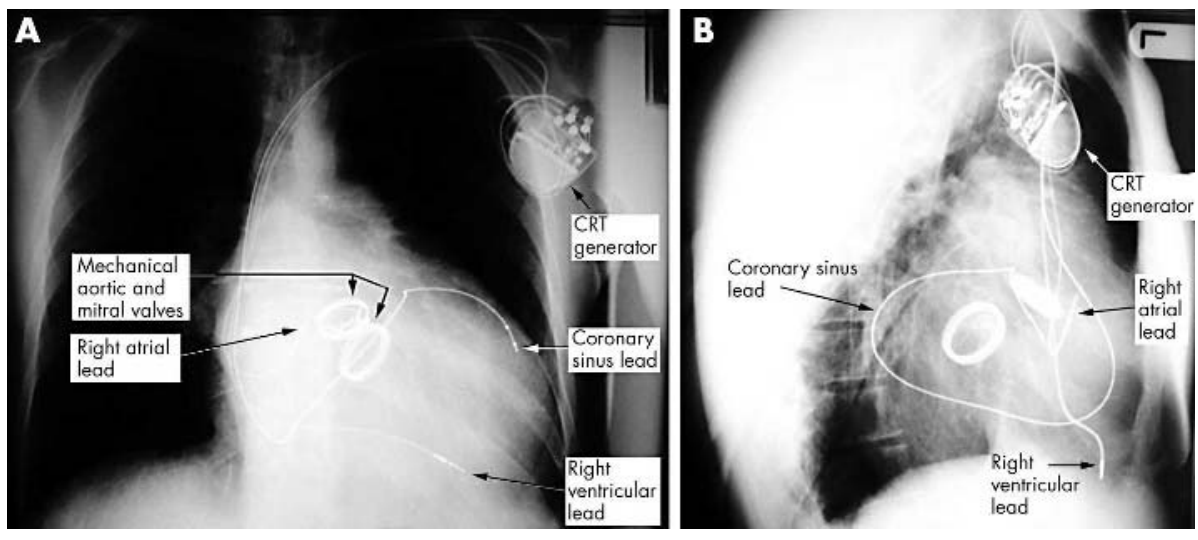

Figure 1 (A) PA chest radiograph showing CRT device and leads in a patient with previous mitral and aortic valve replacement. (B) Lateral chest radiograph of the same patient. 
patients with moderate to severe heart failure, EF $<35 \%$, and QRS durations $>130 \mathrm{~ms}$ were recruited after successful implantation of a CRT device. The patients were randomised to have the device switched on or off to act as controls. In the active treatment group there was a significant improvement in the six minute walk distance $(p=0.005)$, the functional class $(p<0.001)$, quality of life scores $(p=0.001)$, treadmill exercise time $(p=0.001)$, and EF $(p<0.001)$. The active treatment group also required less hospitalisation or intravenous medication $(\mathrm{p}<0.05) .{ }^{81}$ In a sub-study echocardiograms were performed before and after treatment with a CRT device. In the active treatment group the echocardiograms showed a reduced end diastolic and end systolic volumes $(p<0.001)$, decreased LV mass $(p<0.01)$, reduced mitral regurgitation $(p<0.001)$, improved EF $(p<0.001)$, and improved myocardial performance index $(p<0.001){ }^{82}$ Therefore the MIRACLE trial showed that CRT improved both symptoms and echocardiographic appearance in patients with moderate to severe heart failure.

It was hypothesised that CRT might improve prognosis in patients with chronic heart failure attributable to the increase in exercise capacity and peak $\mathrm{VO}_{2}$. When a meta-analysis of the above trials was carried out it showed that CRT led to a significant $51 \%$ reduction in deaths from progressive heart failure (odds ratio (OR) $0.49,95 \%$ confidence intervals (CI) 0.25 to 0.93 ), a significant $29 \%$ reduction in heart failure hospitalisations (OR 0.71 , 95\%CI 0.53 to 0.96 ), and a nonsignificant $23 \%$ reduction in all cause mortality (OR 0.77 , 95\%CI 0.51 to 1.18 ). It also showed that CRT had no effect on non-heart failure mortality (OR 1.15, 95\%CI 0.65 to 2.02) and was not associated with a reduction in ventricular tachycardia or fibrillation (OR $0.92,95 \%$ CI 0.67 to 1.27 ). ${ }^{83}$ Attention thus began to focus on combination devices with both CRT and ICD functions, the latter having been shown to have the greatest impact on mortality in patients fitting selection criteria for the former in MADIT II. Two multicentre randomised trials have evaluated the effect of a combination cardiac resynchronisation and defibrillator device in patients with heart failure, namely the COMPANION trial and the MIRACLE ICD trial.

The COMPANION trial was a three arm study of 1520 patients with NYHA class III/IV heart failure despite optimal treatment. The inclusion criteria were evidence of a conduction system delay on 12 lead ECG (either a PR interval $>150 \mathrm{~ms}$ or a QRS interval >120 ms), LVEF $<35 \%$, end diastolic LV size $>60 \mathrm{~mm}$, and hospitalisation for heart failure in the past year. The patients were randomised to drug treatment only, insertion of a CRT device, or insertion of a combination device. ${ }^{84}$ The results showed that the primary end point (all cause mortality and all cause hospitalisation) was reduced by $19 \%$ in the CRT only group $(p=0.014)$ and by $20 \%$ in the CRT+ICD group $(p=0.01)$. Total mortality was
A
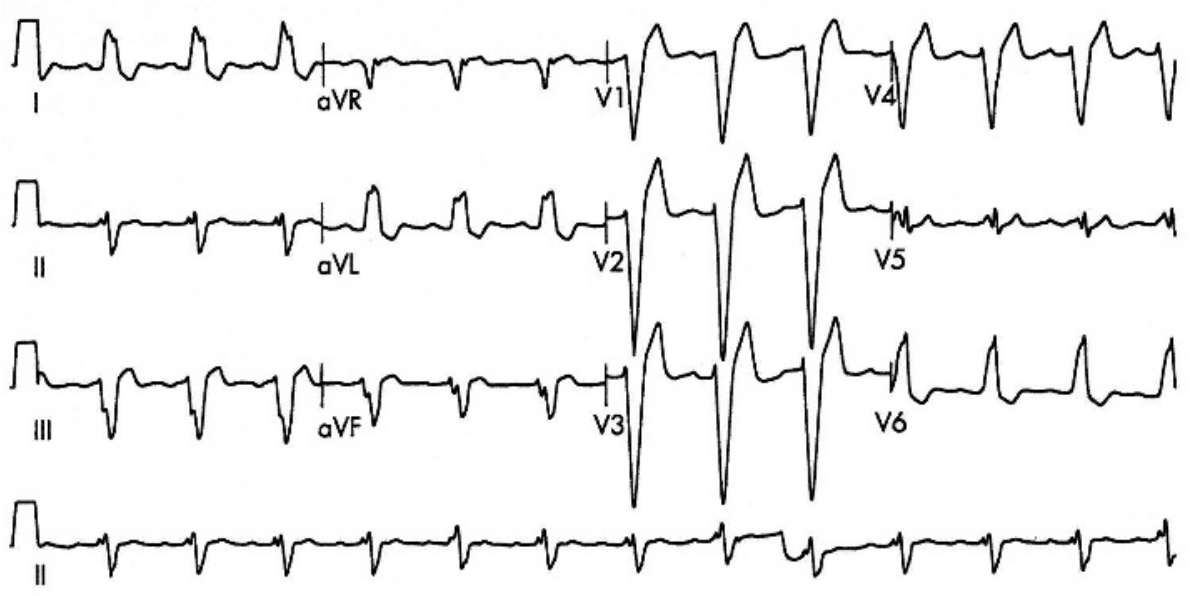

B
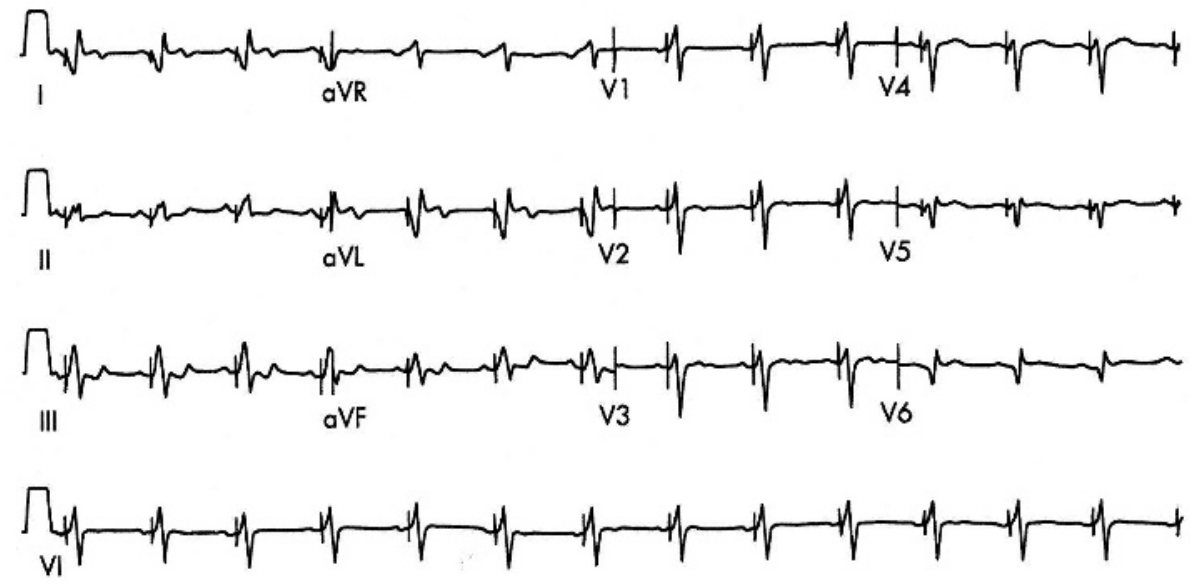

Figure 2 (A) ECG of a patient before CRT with left bundle branch block (LBBB). (B) After CRT ECG of the same patient showing biventicular pacing. 
Current ACC/AHA/NAPSE guidelines for CRT (2002)

- Patients with symptomatic heart failure (New York Heart Association class III or IV) despite optimal medical treatment.

- Prolonged QRS width (greater than $130 \mathrm{~ms}$ ) on 12 lead ECG.

- Left ventricular end diastolic diameter greater than $55 \mathrm{~mm}$.

- Ejection fraction less than $35 \%$.

reduced by a non-significant $24 \%$ in patients receiving CRT alone $(p=0.059)$ and by a significant $36 \%$ in the CRT+ICD group $(\mathrm{p}=0.003) .^{85}$

The MIRACLE ICD trial had 369 patients with NYHA III/IV heart failure on optimal treatment, with an EF $<35 \%$ and a QRS interval $>130 \mathrm{~ms}$. All the patients had a combination device placed, in the control group $(\mathrm{n}=182)$ the CRT portion of the device was switched off, in the active treatment group $(n=187)$ the CRT portion was switched on. All of the patients had the ICD facility switched on. At six months after device implantation, the active treatment group showed improved quality of life scores $(p=0.02)$, improved functional class $(p=0.007)$, improved peak oxygen consumption $(p=0.04)$, and improved exercise function on a treadmill $(\mathrm{p}<0.001)$. No pro-arrhythmiathic tendencies were seen in the active treatment group. In this group there was also no impairment of arrhythmia termination capabilities by the ICD portion. Unfortunately, the MIRACLE ICD trial was not powered or designed to evaluate an effect on mortality. ${ }^{86}$

These two trials therefore showed that combination devices could be used safely to provide a significant improvement in both symptoms and mortality. The current ACC/AHA/NAPSE guidelines for CRT insertion are shown in the box, NICE are currently in the process of establishing guidelines for CRT and these should be available in the near future.

However, the trials have also shown some potential problems. Implantation time is long, median duration in MIRACLE was 2.7 hours. ${ }^{81}$ Placement of a lead in the coronary sinus has proved to be difficult in some patients, with failure rates of between $8 \%$ to $12 \%^{81} 86$ and lead dislodgement in up to a further $12 \% .{ }^{86}$ As operator experience improves and more advanced leads are introduced the failure rate should decrease. However, in a small group the anatomy of the coronary sinus will preclude satisfactory placement of a transvenous lead and an epicardially placed lead must be considered.

The other potential problem identified from the trials above is that around $15 \%-35 \%$ of patients who have a CRT device implanted are non-responders when classic indications are used.$^{87}$ The probable reason for this is that a wide QRS width may not be the most accurate method of evaluating cardiac dyssynchrony. In a recent study it was shown that the presence of intra-LV asynchrony on tissue Doppler echocardiography was an independent predictor of worsening heart failure requiring periodic hospitalisation $(p<0.001)$ and that $56 \%$ of patients with a EF $<45 \%$ but with a normal QRS width $(<120 \mathrm{~ms})$, who would under the current criteria not be suitable for CRT, had evidence of major intra-LV asynchrony, ${ }^{88}$ and therefore were potentially suitable for CRT. When echocardiographic parameters were used to assign patients to CRT treatment it was shown that the response rate increased to $85 \%{ }^{89}$

The treatment options available for heart failure patients, has undergone a substantial increase over the past two decades.
CRT and ICD devices have been shown individually and in combination to improve mortality and morbidity in patients with severe heart failure already receiving optimal medical treatment. They should thus be considered in patients with resistant symptoms and at high risk of sudden death.

\section{Authors' affiliations}

A Y Patwala, D J Wright, The Cardiothoracic Centre, Liverpool, UK

Funding: none.

Conflicts of interest: none declared.

\section{REFERENCES}

1 Davies MK, Hobbs FDR, Davis RC, et al. Prevalence of left-ventricular systolic dysfunction and heart failure in the echocardiographic heart of England screening study: a population based study. Lancet 2001;358:439-44.

2 McMurray JJV, Stewart S. The burden of heart failure. Eur Heart J Suppl 2003;5( suppl I):13-13.

3 Bonneux L, Barendregt JJ, Meeter K, et al. Estimating clinical morbidity due to ischemic heart disease and congestive heart failure: the future rise of heart failure. Am J Public Health 1994:84:20-8.

4 Cleland JGF, Gemmell I, Khand A, et al. Is the prognosis of heart failure improving? Eur J Heart Failure 1999;1:229-41.

5 MERIT-HF Study Group. Effect of metoprolol CR/XL in chronic heart failure: metoprolol CR/XL randomised intervention trial in congestive heart failure (MERIT-HF). Lancet 1999;353:2001-7.

6 Farwell D, Patel NR, Hall A, et al. How many people with heart failure are appropriate for biventricular resynchronization? Eur Heart J 2000;21:1246-50.

7 Stellbrink C, Auricchio A, Diem B, et al. Potential benefit of biventricular pacing in patients with congestive heart failure and ventricular tachyarrhythmia. Am J Cardiol 1999;83:143-50D.

8 Uretsky BF, Sheahan RG. Primary prevention of sudden cardiac death in heart failure: will the solution be shocking? J Am Coll Cardiol 1997;30:1589-97.

9 Levy D, Kenchaiah S, Larson MG, et al. Long-term trends in the incidence of and survival with heart failure. N Engl J Med 2002;347:1397-402.

10 Johnson RA, Palacios I. Dilated cardiomyopathies of the adult ( 1 st of 2 parts). N Engl J Med 1982;307:1051-8.

11 McKee PA, Castelli WP, McNamara PM, et al. The natural history of congestive heart failure: the Framingham study. N Engl J Med 1971;285:1441-6.

12 National Institute for Clinical Evidence. Management of chronic heart failure in adults in primary and secondary care. http://www.nice.org.uk/pdf/ CG5NICEguideline.pdf.

13 Bohm M, Kilter H, Kindermann M. Mechanisms contributing to the progression of left ventricular dysfunction to end-stage heart failure. Eur Heart J Suppl, 2003;5(suppl I) 14-21.

14 Garg R, Yusuf S. Overview of randomized trials of angiotensin-converting enzyme inhibitors on mortality and morbidity in patients with heart failure. JAMA 1995;273:1450-6.

15 van Kats JP, Danser AHJ, van Meegen JR, et al. Angiotensin production by the heart. Circulation 1998;98:73-81.

16 Jong P, Demers C, McKelvie RS, et al. Angiotensin receptor blockers in heart failure: meta-analysis of randomized controlled trials. J Am Coll Cardiol 2002;39:463-70.

17 CIBIS Investigators and Committees. A randomised trial of beta-blockade in heart failure. The cardiac insufficiency bisoprolol study (CIBIS). Circulation 1994;90:1765-73.

18 Packer M, Bristow M, Cohn J, et al. The effect of carvedilol on morbidity and mortality in patients with chronic heart failure. N Engl J Med 1996;334:1349-55.

19 CIBIS-II Investigators and Committees. The cardiac insufficiency bisoprolol study II (CIBIS-II): a randomised trial. Lancet 1999;353:9-13.

20 Pitt B, Zannad F, Remme WJ, et al. The effect of spironolactone on morbidity and mortality in patients with severe heart failure. N Engl J Med 1999;341:709-17

21 Pitt B, Remme W, Zannad F, et al. Eplerenone: a selective aldosterone blocker, in patients with left ventricular dysfunction after myocardial infarction. N Engl J Med 2003;348:1309-21.

22 The Digitalis Investigation Group. The effect of digoxin on mortality and morbidity in patients with heart failure. N Engl J Med 1997;336:525-33.

23 Philbin EF, Andreou C, Rocco TA, et al. Patterns of angiotensin-converting enzyme inhibitor use in congestive heart failure in two community hospitals. Am J Cardiol 1996;77:832-8.

24 Smith NL, Psaty BM, Pitt B, et al. Temporal patterns in the medical treatment of congestive heart failure with angiotensin-converting enzyme inhibitors in older adults, 1989 through 1995. Arch Intern Med 1998;158:1074-80.

25 Packer M. Do angiotensin-converting enzyme inhibitors prolong life in patients with heart failure treated in clinical practice. J Am Coll Cardiol 1996;28:1323-7

26 Kjekshus J, Swedberg K. Tolerability of enalapril in congestive heart failure. Am J Cardiol 1988;62:67-72A.

27 O'Connell JB, Bristow MR. Economic impact of heart failure in the United States: time for a different approach. J Heart Lung Transplant 1994; 13:S107-12. 
28 Packer M, Poole-Wilson PA, Armstrong PW, et al. Comparative effects of low and high doses of the angiotensin-converting enzyme inhibitor, lisinopril, on morbidity and mortality in chronic heart failure. Circulation 1999:100:2312-18.

29 The CONSENSUS trial group. Effect of enalapril on mortality in severe congestive heart failure. Results of the cooperative north Scandinavian enalapril survival study (CONSENSUS). N Engl J Med 1987;316:1429-35.

30 Bradley DJ. Combining resynchronization and defibrillation therapies for heart failure. JAMA 2003;289:2719-21.

31 Cohn JN, Archibald DG, Ziesche S, et al. Effect of vasodilator therapy on mortality in chronic congestive heart failure. Results of a Veterans Administration cooperative study. N Engl J Med 1986;314:1547-52

32 Cohn JN, Johnson G, Ziesche S, et al. A comparison of enalapril with hydralazine-isosorbide dinitrate in the treatment of chronic congestive heart failure. N Engl J Med 1991;325:303-10.

33 Uretsky BF, Thygesen K, Armstrong PW, et al. Acute coronary findings at autopsy in heart failure patients with sudden death. Circulation 2000; 102:611-16.

34 Echt DS, Liebson PR, Mitchell LB, et al. Mortality and morbidity in patients receiving encainide, flecainide, or placebo. The cardiac arrhythmia suppression trial. N Engl J Med 1991;324:781-8.

35 The Cardiac Arrhythmia Suppression Trial II Investigators. Effect of the antiarrhythmic agent Moricizine on survival after myocardial infarction. N Engl J Med 1992:327:227-33.

36 Burkart $F$, Pfisterer $M$, Kiowski W, et al. Effect of antiarrhythmic therapy on mortality in survivors of myocardial infarction with asymptomatic complex ventricular arrhythmias: Basel antiarrhythmic study of infarct survival (BASIS) J Am Coll Cardiol 1990;16:1711-18.

37 Doval HC, Nul DR, Grancelli HO, et al. Randomised trial of low dose amiodarone in severe congestive heart failure. Lancet 1994;344:493-8.

38 Garguichevich JJ, Ramos JL, Gambarte A, et al. Effect of amiodarone therapy on mortality in patients with left ventricular dysfunction and asymptomatic complex ventricular arrhythmias: Argentine pilot study of sudden death and amiodarone (EPAMSA). Am Heart J 1995; 130:494-500.

39 Elizari MV, Martinez JM, Belziti C, et al. Morbidity and mortality following early administration of amiodarone in acute myocardial infarction. GEMICA study. Eur Heart J 2000;21:198-205.

40 Julian DG, Camm AJ, Frangin G, et al. Randomised trial of effect of amiodarone on mortality in patients with left-ventricular dysfunction after recent myocardial infarction: EMIAT. Lancet 1997;349:667-74.

41 Cairns JA, Connolly SJ, Roberts R, et al. Randomised trial of outcome after myocardial infarction in patients with frequent or repetitive ventricular premature depolarisations: CAMIAT. Lancet 1997;349:675-82.

42 Ceremuzynski L, Kleczar E, Krzeminska-Pakula M, et al. Effect of amiodarone on mortality after myocardial infarction: a double-blind, placebo-controlled, pilot study. J Am Coll Cardiol 1992;20:1056-62.

43 Navarro-Lopez F, Cosin J, Marrugat J, et al. Comparison of the effect of amiodarone versus metoprolol on the frequency of ventricular arrhythmias and on mortality after acute myocardial infarction. Am J Cardiol 1993;72:1243-8.

44 Hockings BE, George T, Mahrous F, et al. Effectiveness of amiodarone on ventricular arrhythmias during and after acute myocardial infarction. Am J Cardiol 1987;60:967-70.

45 Cairns JA, Connolly SJ, Gent M, et al. Post myocardial infarction mortality in patients with ventricular premature depolarizations. Canadian amiodarone myocardial infarction arrhythmia trial pilot study. Circulation 1991:84:550-7.

46 Singh SN, Fletcher RD, Fisher SG, et al. Amiodarone in patients with congestive heart failure and asymptomatic ventricular arrhythmia. NEngl J Med 1995;333:77-82.

47 Nicklas JM, McKenna WJ, Stewart RA, et al. Prospective, double-blind, placebo-controlled trial of low-dose amiodarone in patients with severe heart failure and asymptomatic frequent ventricular ectopy. Am Heart $J$ $1991 ; 122: 1016-21$

48 Hamer AW, Arkles B, Johns JA. Beneficial effects of low dose amiodarone in patients with congestive cardiac failure: a placebo-controlled trial. J Am Coll Cardiol 1989;14:1768-74.

49 Connolly SJ. Meta-analysis of antiarrhythmic drug trials. Am J Cardiol 1999;84:90-3R.

50 The AVID investigators. A comparison of antiarrhythmic-drug therapy with implantable defibrillators in patients resuscitated from near fatal ventricular arrhythmias. N Engl J Med 1997;337:1576-83.

51 Connolly SJ, Gent M, Roberts RS, et al. Canadian implantable defibrillator study (CIDS). Circulation 2000;101:1297-302.

52 Kuck KH, Cappato R, Siebels J, et al. Randomised comparison of antiarrhythmic drug therapy with implantable defibrillators in patients resuscitated from cardiac arrest. Circulation 2000;102:748-54.

53 Connolly SJ, Hallstrom AP, Cappato R, et al. Meta-analysis of the implantable cardioverter defibrillator secondary prevention trials. Eur Heart $J$ 2000;21:2071-8.

54 Moss AJ, Hall WJ, Cannom DS, et al. Improved survival with an implanted defibrillator in patients with coronary disease at high risk for ventricular arrhythmia. N Engl J Med 1996;335:1933-40.

55 Buxton AE, Lee KL, Fisher JD, et al. A randomized study of the prevention of sudden death in patients with coronary artery disease. N Engl J Med 1999;341:1882-90.

56 Klein HU, Reek S. The MUSTT study: evaluating, testing and treatment. J Interven Card Electophysiol 2000;4:45-50.

57 Moss AJ, Daubert J, Zareba W. MADIT-II: clinical implications. Cardiol Electrophysiol Rev 2002;6:463-5.
58 Moss AJ, Zareba W, Hall WJ, et al. Prophylactic implantation of a defibrillator in patients with myocardial infarction and reduced ejection fraction. $N$ Engl J Med 2002;346:877-83.

59 Moss AJ. Findings from the MADIT-II substudies. Eur Heart J Suppl 2003;5(suppl I):134-8.

60 Bardy GH. SCD-HeFT: the sudden cardiac death in heart failure trial. http:// www.acc04online.acc.org.

61 Dougherty CM. Psychological reactions and family adjustment in shock versus no shock groups after implantation of internal cardioverter defibrillator. Heart Lung 1995;24:281-91.

62 Pacifico A, Hohnloser SH, Williams JH, et al. Prevention of implantable defibrillator shocks by treatment with Sotalol. N Engl J Med 1999;340:1855-62.

63 The CASCADE investigators. Randomized antiarrhythmic drug therapy in survivors of cardiac arrest. Am J Cardiol 1993;72:280-7.

64 Kass DA. Ventricular remodelling: chamber dyssynchrony and effects of cardiac resynchronization. Eur Heart J Suppl 2003;5(suppl I):154-63.

65 Nelson GS, Berger RD, Fetics BJ, et al. Left ventricular or biventricular pacing improves cardiac function at diminished energy cost in patients with dilated cardiomyopathy and left bundle-branch block. Circulation 2000;102:3053-9.

66 Hare JM. Cardiac resynchronization therapy for heart failure. N Engl J Med 2002;346:1902-05

67 Gottipaty VK, Krelis SP, Lu F, et al. The resting electrocardiogram provides a sensitive and inexpensive marker of prognosis in patients with chronic congestive heart failure. (Abstract). J Am Coll Cardiol 1999;33:847-4.

68 Cazeau S, Ritter P, Lazarus A, et al. Multisite pacing for end-stage heart failure: early experience. Pacing Clin Electrophysiol 1996;19:1748-57.

69 Kass DA, Chen CH, Curry C, et al. Improved left ventricular mechanics from acute VDD pacing in patients with dilated cardiomyopathy and ventricular conduction delay. Circulation 1999;99:1567-73

70 Blanc JJ, Etienne Y, Gilard M, et al. Evaluation of different ventricular pacing sites in patients with severe heart failure. Circulation 1997:96:3273-7.

71 Auricchio A, Stellbrink C, Block M, et al. Effect of pacing chamber and atrioventricular delay on acute systolic function of paced patients with congestive heart failure. Circulation 1999;99:2993-3001.

72 Leclercq C, Kass DA. Retiming the failing heart: principles and current clinical status of cardiac resynchronization. J Am Coll Cardiol 2002;39:194-201.

73 Auricchio A, Stellbrink C, Sack S, et al. Long term clinical effects of hemodynamically optimised cardiac resynchronization therapy in patients with heart failure and ventricular conduction delay. J Am Coll Cardiol 2002;39:2026-33.

74 Cazeau S, Leclercq C, Lavergne T, et al. Effect of multisite biventricular pacing in patients with heart failure and intraventricular conduction delay. N Engl J Med 2001;344:873-80

75 Gras D, Leclercq C, Tang ASL, et al. Cardiac resynchronization therapy in advanced heart failure the multicenter InSync clinical study. Eur J Heart Fail 2002;4:311-20.

76 Nelson GS, Berger RD, Fetics BJ, et al. Left ventricular pre-excitation improves mechanoenergetics of patients with dilated cardiomyopathy and ventricular conduction delay. (Abstract). J Am Coll Cardiol 2000;35:901-2.

77 Toussaint JF, Ritter P, Lavergne T, et al. Biventricular resynchronization in endstage heart failure: an eight-months follow up by phase map radionuclide angiography. (Abstract). Pacing Clin Electrophysiol 1999;22:561.

78 Curry CW, Nelson GS, Wyman BT, et al. Mechanical dyssynchrony in dilated cardiomyopathy with intraventricular conduction delay as depicted by 3D tagged magnetic resonance imaging. Circulation 2000;101:e2.

79 Breithardt OA, Stellbrink C, Diem B, et al. Effect of chronic multisite pacing on left ventricular volumes in patients with congestive heart failure. (Abstract). Pacing Clin Electrophysiol 1999;22:131

80 Stellbrink C, Breithardt OA, Diem B, et al. Acute effects of multisite pacing with different $A V$ delays on diastolic and systolic functions in congestive heart failure. (Abstract). Pacing Clin Electrophysiol 1999;22:516.

81 Abraham WT, Fisher WG, Smith AL, et al. Cadiac resynchronization in chronic heart failure. N Engl J Med 2002;346:1845-53.

82 Sutton St John MG, Plappert T, Abraham WT, et al. Effect of cardiac resynchronization therapy on left ventricular size and function in chronic heart failure. Circulation 2003;107:1985-90.

83 Bradley DJ, Bradley EA, Baughman KL, et al. Cardiac resynchronization and death from progressive heart failure. A meta-analysis of randomised controlled trials. JAMA 2003;289:730-40.

84 Bristow MR, Feldman AM, Saxon LA. Heart failure management using implantable devices for ventricular resynchronization: comparison of medical therapy, pacing and defibrillation in chronic heart failure (COMPANION) trial. J Cardiac Failure 2000;6:276-85.

85 Bristow MR, Saxon LA, Boehmer J, et al. Cardiac-resynchronization therapy with or without an implantable defibrillator in advanced chronic heart failure. N Engl J Med 2004;350:2140-50.

86 Young JB, Abraham WT, Smith A, et al. Combined cardiac resynchronization and implantable cardioversion defibrillation in advanced chronic heart failure. The MIRACLE ICD trial. JAMA 2003;289:2685-94.

87 Rivero-Ayerza M, De Backer T, Vanderheyden M, et al. Indications for cardiac resynchronization therapy: should they be extended? Eur Heart J Suppl 2003;5(suppl I):197-101.

88 Bader H, Garrigue S, Lafitte S, et al. Intra-left ventricular electromechanical asynchrony. A new independent predictor of severe cardiac events in heart failure patients. J Am Coll Cardiol 2004;43:248-56.

89 Cazeau S, Bordaghar P, Jauvert G, et al. Echocardiographic modelling of cardiac dyssynrony before and during multisite stimulation. Pacing Clin Electrophysiol 2003;26:137-43. 